\title{
Afatinib demonstrates remarkable activity against HER2-amplified uterine serous endometrial cancer in vitro and in vivo
}

\author{
C L Schwab ${ }^{1}$, S Bellone ${ }^{1}$, D P English ${ }^{1}$, D M Roque ${ }^{1}$, S Lopez $^{2}$, E Cocco ${ }^{1}$, R Nicoletti ${ }^{1}$, I Bortolomai $^{3}$, \\ E Bonazzoli ${ }^{1}$, E Ratner ${ }^{1}$, D-A Silasi ${ }^{1}$, M Azodi ${ }^{1}$, P E Schwartz ${ }^{1}$, T J Rutherford ${ }^{1}$ and A D Santin ${ }^{*}, 1$ \\ ${ }^{1}$ Department of Obstetrics, Gynecology and Reproductive Sciences, Yale School of Medicine, 333 Cedar Street, New Haven, \\ CT 06520, USA; ${ }^{2}$ Division of Gynecologic Oncology, University Campus Biomedico of Roma, Via Álvaro del Portillo, 21, 00128 \\ Rome, Italy and ${ }^{3}$ Telethon Institute for Gene Therapy (TIGET), Ospedale San Raffaele, Via Olgettina, 60, 20132 Milan, Italy
}

Background: Uterine serous carcinomas (USCs) are an aggressive form of uterine cancer that may rely on HER2/neu amplification as a driver of proliferation. The objective of this paper is to assess the sensitivity of USC cell lines with and without HER2/neu gene amplification to afatinib, an irreversible ErbB tyrosine kinase inhibitor, and to test the efficacy of afatinib in the treatment of HER2amplified USC xenografts.

Methods: Eight of fifteen primary USC cell lines (four with HER2 amplification and four without) demonstrating similar in vitro growth rates were treated with scalar concentrations of afatinib. Effects on cell growth, signalling and cell cycle distribution were determined by flow cytometry assays. Mice harbouring xenografts of HER2/neu-amplified USC were treated with afatinib by gavage to determine the effect on tumour growth and overall survival.

Results: Primary chemotherapy-resistant USC cell lines harbouring HER2/neu gene amplification were exquisitely sensitive to afatinib exposure (mean \pm s.e.m. $I C_{50}=0.0056 \pm 0.0006 \mu \mathrm{M}$ ) and significantly more sensitive than HER2/neu-non-amplified USC cell lines (mean \pm s.e.m. $I C_{50}=0.563 \pm 0.092 \mu \mathrm{M}, P<0.0001$ ). Afatinib exposure resulted in abrogation of cell survival, inhibition of HER2/neu autophosphorylation and S6 transcription factor phosphorylation in HER2/neu overexpressing USC and inhibited the growth of HER2-amplified tumour xenografts improving overall survival $(P=0.0017)$.

Conclusions: Afatinib may be highly effective against HER2/neu-amplified chemotherapy-resistant USC. The investigation of afatinib in patients harbouring HER2/neu-amplified USC is warranted.

Uterine serous carcinoma (USC) is a highly malignant variant of endometrial cancer characterised by an aggressive biologic behaviour and an inborn or rapidly acquired resistance to chemotherapy (Levenback et al, 1992; Nicklin and Copeland, 1996; Schwartz, 2006). Although uterine serous cancer is not as common as the endometrioid histotype it accounts for $40 \%$ of deaths caused by endometrial cancer (Hamilton et al, 2006; Schwartz, 2006). After undergoing surgical staging, patients are usually treated with chemotherapy or a combination of chemotherapy and radiation therapy (Goff, 2005; Schwartz, 2006). Despite aggressive adjuvant therapy the recurrence rate of uterine serous cancer is $\sim 50 \%$, which is higher than its endometrioid counterpart (Acharya et al, 2005). Stage for stage USC, compared with endometrioid carcinoma, portends a worse 5-year survival rate (Acharya et al, 2005; Goff, 2005). Given this cancer's aggressive nature, high rate of recurrence and mortality new treatments are being sought.

Targeted therapy for cancer has been the focus of much research over the past decade. Through the use of next-generation sequencing technology molecularly targeted therapies are being developed and studied around the world. Through these new technologies, therapies are being developed to exploit mutated or 
upregulated driver pathways associated with particular cancers. Uterine serous cancers are no exception (Black et al, 2014). While targeted therapies are being developed, new drugs have been brought to market that target cell surface receptors associated with driver pathways, especially those in the ErbB receptor family. This remains an attractive therapeutic approach because it offers a higher level of specificity and decreases many associated toxicities found with conventional cytotoxic chemotherapy. The enthusiasm for targeting cell surface receptors has not waned particularly in head and neck, gastric, lung, and breast cancers (Regales et al, 2009; Reungwetwattana and Dy, 2013; Cohen, 2014; Modjtahedi et al, 2014). As a result, new small molecule tyrosine kinase inhibitors have been developed to target the receptors associated with these dysregulated pathways.

Uterine serous carcinomas have been reported to overexpress HER2/neu in one-third of cases (Santin et al, 2005; Buza et al, 2013) Overexpression of HER2/neu has also been associated with cancers that act more aggressively (Wright et al, 1989; Berchuck et al, 1990; Hetzel et al, 1992; Tanner et al, 2005; Engelsen et al, 2008). This overexpression leads to increased receptor homo- and hetero-dimerisation with other ErbB family member receptors leading to autophosphorylation, sustained signalling, and activation of transcription factors with resultant increased proliferation (Mitri et al, 2012; Hartman et al, 2013). Targeting HER2/neu and the remainder of the ErbB family with a receptor specific inhibitor could potentially mitigate the aggressive nature of HER2/neuamplified USC, effectively turn off proliferation, and ultimately lead to tumour death.

Afatinib (BIBW-2992) is a drug recently approved by the FDA as a first-line treatment of ErbB1-mutated non-small cell lung cancer (Dungo and Keating, 2013). Unlike previous HER2-specific compounds, which targeted extracellular receptor domains, afatinib works by covalently binding to intracellular phosphorylation sites of ErbB1, 2, and 4 as well as inhibiting transphosphorylation of ErbB3 (Dungo and Keating, 2013). Taken as a once daily tablet, its spectrum of activity has the potential to decrease the rates of HER2 homo- and hetero-dimerisation to a far greater extent than that previously demonstrated by HER2/neuspecific antibodies. Previously published data support this idea in multiple tumour types (Modjtahedi et al, 2014). Covalent binding of afatinib to the intracellular tyrosine kinase domain interrupts the signalling cascade and results in decreased proliferation and tumour growth.

The aim of this study is to determine, the efficacy of afatinib in treating HER2/neu-amplified USC $v s$-non-amplified USC both in vitro and in vivo and the downstream effects on the intracellular signalling pathway, as well as changes in cell cycle distribution.

\section{MATERIALS AND METHODS}

Collection of tumours, establishment of primary USC cell lines, and assessment of HER2/neu status. Patients were consented for tumour banking before the surgery. At frozen section, core samples of each tumour were collected under approval of the institutional review board. These tumours were processed such that portions of the tumour were saved for genetic analysis, immunohistochemistry (IHC) studies and a portion homogenised and reconstituted in petri dishes to establish primary cell lines. Cell lines were grown and established in a culture media of RPMI 1640 (Gibco Life Technologies, Grand Island, NY, USA) with $10 \%$ foetal bovine serum (FBS) (Gemini, Woodland, CA, USA), 1\% penicillin/ streptomycin (Gibco Life Technologies), and 1\% amphotericin B (Gibco Life Technologies). Fifteen primary USC cell lines were analysed by using IHC, flow cytometry, and FISH assays to assess the level of expression of the HER2/neu receptor as described previously (English et al, 2013). Primary USC cell lines (four with HER2 gene amplification and four without) demonstrating similar in vitro growth rates were selected for analysis.

Drug. Afatinib (BIBW-2992) free base was obtained from Selleckchem (Houston, TX, USA). It was diluted to a solution of $10 \mathrm{~mm}$ in DMSO to create a stock solution. Serial dilutions of the stock solution were made at the following concentrations: $1 \mathrm{mM}$, $0.1 \mu \mathrm{M}, 0.05 \mu \mathrm{M}$, and $0.005 \mu \mathrm{M}$.

Chemo-response assays. Cell cultures of the eight cell lines to be tested were established. They were harvested during the log growth phase and plated in six-well plates for chemotherapy response assays. HER2-amplified and -non-amplified cell lines were grown in a monolayer at the starting concentration of $20000 \mathrm{cells} \mathrm{ml}^{-1}$ using RPMI 1640 with $10 \%$ FBS and 1\% penicillin/streptomycin and $1 \%$ amphotericin B. After 24-h incubation they were subsequently treated with scalar concentrations of afatinib ranging from 0.005 to $2 \mu \mathrm{M}$ for $72 \mathrm{~h}$. At the 72 -h time point, the entirety of the samples were collected and centrifuged. The effect on cell viability was determined by staining with propidium iodide $(2 \mu \mathrm{l}$ of $500 \mu \mathrm{g} \mathrm{ml}^{-1}$ stock solution in PBS with $1 \%$ azide and $2 \%$ FBS) and reading each sample by using flow cytometry to quantify percent viable cells as a mean \pm s.e.m. relative to vehicle treated cells as $100 \%$ viable controls. The $\mathrm{IC}_{50}$ for each cell line was then calculated by using Graph Pad Prism 5 (Graph Pad Prism Software Inc., San Diego, CA, USA). Each experiment was performed in triplicate and repeated a minimum of three times per cell line.

HER2/neu and S6 phosphorylation. Cells were plated at 250000 cells $\mathrm{ml}^{-1}$ of media into six-well plates. They were allowed to incubate for $24 \mathrm{~h}$. Cells were then treated with afatinib at concentrations of $0.005,0.050$, and $0.175 \mu \mathrm{M}$. After incubation for $2,4,8,10,12$, and $16 \mathrm{~h}$ they were harvested. Cells were fixed using $4 \%$ paraformaldehyde for $10 \mathrm{~min}$ at $37^{\circ} \mathrm{C}$. They were then washed with PBS and permeabilised with 90\% methanol. They were suspended in incubation buffer (PBS containing 0.5\% BSA), blocked for $10 \mathrm{~min}$, and aliquoted into three different tubes. Cells were allowed to incubate with primary antibody to P-HER2/neu1221, P-S6 (Cell Signaling Technologies, Danvers, MA, USA), or no primary antibody for $1 \mathrm{~h}$ on ice. Cells were then washed in incubation buffer three times and allowed to incubate with secondary fluorescein-conjugated antibody (Millipore, Darmstadt, Germany) for $1 \mathrm{~h}$ on ice. Samples were then washed, suspended in PBS, and read by using flow cytometry. Mean fluorescent intensities (MFIs) were then calculated by using BD Cell Quest Pro software (BD Biosciences, San Jose, CA, USA). Differences in MFI between groups and treatments were then compared between the groups.

ErbB1 expression. Cells from each cell line were placed in $5 \mathrm{~cm}^{3}$ flow cytometer tubes at a concentration of 250000 cells. Cells were washed and suspended in PBS and 0.5\% BSA. They were then labelled with cetuximab or rituximab (negative control) at a concentration of $2 \mu \mathrm{g} \mathrm{ml}^{-1}$ and $5 \mu \mathrm{g} \mathrm{ml}^{-1}$, respectively. The cells were allowed to incubate for $1 \mathrm{~h}$ on ice. They were washed and stained with a secondary fluorescein-conjugated antibody for $1 \mathrm{~h}$ on ice. They were then read by using flow cytometry and analysed using BD cell quest pro software. Differences in MFI were then compared between the groups.

Cell cycle analysis. Cells were plated in six-well plates at a concentration of $20000 \mathrm{cells} \mathrm{ml}^{-1}$. They were allowed to incubate for $24 \mathrm{~h}$. Scalar amounts of afatinib were then placed in each well. Cultures were allowed to incubate for $40 \mathrm{~h}$ and harvested for analysis. Cells were fixed in $70 \%$ ethanol for $30 \mathrm{~min}$ on ice. Cells were then washed with PBS three times and then treated with $100 \mu \mathrm{l}$ of ribonuclease in PBS at a concentration of $100 \mu \mathrm{g} \mathrm{ml}^{-1}$ at room temperature over $5 \mathrm{~min}$. Propidium iodide, diluted to a 
concentration of $50 \mu \mathrm{g} \mathrm{ml}^{-1}$ in PBS, was then added to each sample to reach a final volume of $500 \mu \mathrm{l}$. Cell cycle was then analysed by flow cytometry using BD Cell Quest Pro software. Finally data were analysed by using Flowjo (Flowjo LLC, Ashland, OR, USA).

In vivo studies. Ten-week-old SCID mice (Harlan Netherlands, Horst, The Netherlands) were housed and treated in accordance with Institutional Animal Care and Use Committee (IACUC) policies at Yale University. All in vivo procedures were reviewed and approved by IACUC animal ethics review board at Yale University. Mice were divided into two groups that included those treated with afatinib by oral gavage at $25 \mathrm{mg} \mathrm{kg}^{-1}$ per day and those treated with vehicle sterile water with $0.5 \%$ methylcellulose. Each group was treated 5 days a week. Uterine serous carcinoma cell line ARK2 was expanded in $150 \mathrm{ml}$ flasks. Cells were harvested and suspended in a $1: 1$ solution of PBS and Matrigel (BD Biosciences). Mice were injected in the lower abdominal subcutaneous space with 8.4 million tumour cells. Tumours were allowed to establish over the course of 10 days and treatment began when the greatest tumour dimension was at least $0.5 \mathrm{~cm}$. Tumours were assessed at least twice weekly and measured in two dimensions. Mice were killed if tumours reached $1 \mathrm{~cm}^{3}$ by using the formula height $\times$ width $\times$ width $\times 0.5$, appeared necrotic or if the animal was in poor health.

Statistical analysis. Statistical analysis was completed by using Graph Pad Prism 5. All $\mathrm{IC}_{50}$ data were analysed by first normalising the number of live cells in each well treated with drug to the number of live cells in the untreated control. Using Prism, normalised data were fit to nonlinear 3-parameter logistic dose-response curves against the base-10 logarithms of dose in micromolar. The resulting parameter estimates were used to calculate the $\mathrm{IC}_{50}$ in $\log _{10}$ units for each experiment. Unpaired two-sided Student's $t$-tests were used to compare the differences in the MFIs of EGFR, P-HER2, and p-S6. Overall survival was analysed by using a Kaplan-Meir curve and log rank tests. One way analysis of variance was used to compare the $\mathrm{IC}_{50}$ data of HER2-amplified $v s$-non-amplified cell lines, whereas group means were compared using Student's $t$-test. Differences in all comparisons were considered statistically significant if $P<0.05$.

\section{RESULTS}

Selection of cell lines and determination of sensitivity to afatinib. We have recently sequenced (whole-genome sequencing) a series of uterine serous tumour that were harvested at the time of surgery (Zhao et al, 2013). Cell lines established from these tumours were selected on the basis of differential expression of HER2/neu detected by IHC and confirmed by FISH analysis based upon our previously published data (English et al, 2013). Five of fifteen established cell lines showed amplification of HER2/neu of which four were selected as experimental cell lines because of their similar growth rates (English et al, 2013). Cell lines that were not amplified and had varying expression of HER2/neu were selected as controls. A total of four HER2/neu-amplified and -nonamplified cell lines were identified. The characteristics of the cell lines and patient's tumours from which they were established are described in Table 1.

Data regarding these two groups of cell lines response to afatinib were first established by determining each individual cell line's $\mathrm{IC}_{50}$. Final analysis of HER2/neu-amplified cell lines revealed that they were $\sim 100$-fold more sensitive to afatinib in vitro than their non-amplified counterpart (Figure 1A). Taking each individual $\mathrm{IC}_{50}$ value (three for each cell line) for all eight cell lines and examining mean $\mathrm{IC}_{50}$ for HER2-amplified $v s$-non-amplified, the mean $\mathrm{IC}_{50}$ 's were $0.0056 \pm 0.0006 \mu \mathrm{M}$ and $0.563 \pm 0.092 \mu \mathrm{M}$
Table 1. Characteristics of patients from which primary cell lines were derived

\begin{tabular}{|l|c|c|c|l|}
\hline Cell line & Age & Stage & IHC & FISH \\
\hline ARK2 & 63 & IV & $3+$ & Amplified \\
\hline ARK3 & 59 & IV & $3+$ & Amplified \\
\hline ARK20 & 42 & II & $3+$ & Amplified \\
\hline ARK21 & 70 & IA & $3+$ & Amplified \\
\hline ARK7 & 75 & IIC & $2+$ & Non-amplified \\
\hline ARK11 & 80 & IIIC & $1+$ & Non-amplified \\
\hline ARK19 & 65 & IA & $2+$ & Non-amplified \\
\hline ARK22 & 60 & IVB & $0+$ & Non-amplified \\
\hline
\end{tabular}

Abbreviation: $\mathrm{IHC}=$ immunohistochemistry; $\mathrm{FISH}=$ fluorescence in situ hybridisation.

$(P<0.0001)$, respectively (Figure $1 \mathrm{~B})$. These data suggest that USC cell lines that overexpress HER $2 /$ neu and rely on its amplification for proliferation are exquisitely sensitive to afatinib in vitro.

Alterations in cell cycle distribution with afatinib treatment. Cell cycle analysis was performed using ARK2 as the representative HER2-amplified cell line, whereas ARK11 was chosen as the nonamplified control cell line. These two cell lines were chosen based on their differential expression of HER2/neu and nearly identical doubling time of ARK2 18.2 h vs ARK11 23.1 h (data not shown). ARK2 data revealed that there is a significant build up in the G0/G1 phase of the cell cycle with even low levels $(25 \mathrm{~nm})$ of afatinib compared with untreated samples mean $42.6 \pm 0.20 \%$ vs $30.4 \pm 0.32 \% \quad(P=0.001)$. Assays using ARK11 showed no significant change in the cell cycle distribution using relevant human physiologic concentrations of afatinib (50 nM) in treated and untreated controls $34.9 \pm 0.37 \%$ vs $33.9 \pm 1.33 \%(P=0.51)$, respectively. These results suggest that afatinib treatment inhibits the HER2-amplified cell line's rapid progression through the cell cycle by binding and inhibiting the driver pathway HER2/neu.

Expression of ErbB1 in HER2/neu-amplified and -non-amplified cell lines. Given afatinib's broad mechanism of action and the frequency of ErbB1 expression in gynecologic tumours, it is important to examine the possibility of differential expression of ErbB1 between the two groups of cell lines. Previously published sequencing data showed that the HER2/neu-amplified cell lines did not harbour mutations in EGFR and that the receptor was not amplified (Zhao et al, 2013). Furthermore, flow cytometry data revealed that ErbB1 receptor expression was not significantly different between the two groups (Figure 2); HER2-amplified MFI $38.3 \pm 4.6$ and HER2 non-amplified MFI $33.1 \pm 8.1(P=0.38)$. These data support the conclusion that afatinib's efficacy, in this in vitro model, is mostly exerted through inhibition of the differentially expressed HER2/neu receptor.

Alterations in HER2/neu and S6 phosphorylation after treatment with afatinib. The phosphorylation of HER2/neu and downstream phosphorylation of the transcription factor S6 were assessed by using flow cytometry. By using time points from previously published studies on afatinib, the drug's differential effect on the phosphorylation of the transcription factor S6 was first determined for ARK2 and ARK11 (Takezawa et al, 2012). At $8 \mathrm{~h}$ there was a clear effect on the phosphorylation of S6 for the HER2-amplified cell line ARK2 but not for ARK11 using low concentrations of afatinib (Figure 3A and B). These experiments were replicated in ARK2 using doses of afatinib on the basis of data regarding mean serum levels of afatinib achieved in humans after $24 \mathrm{~h}$ and 28 days of 40 or $50 \mathrm{mg}$ of afatinib daily. These concentrations were based on previously published reports, 37-91 nM after $24 \mathrm{~h}$ and $170 \mathrm{~nm}$ after 28 days of treatment (Regales et al, 2009). Time-course assays, 


A
\begin{tabular}{|c|c|c|c|c|c|c|c|c|}
\hline & Ark 2 & Ark 3 & Ark 20 & Ark 21 & Ark 7 & Ark 11 & Ark 19 & Ark 22 \\
\hline Mean & 0.004092 & 0.003736 & 0.007118 & 0.007423 & 1.052 & 0.3992 & 0.4831 & 0.3198 \\
\hline
\end{tabular}
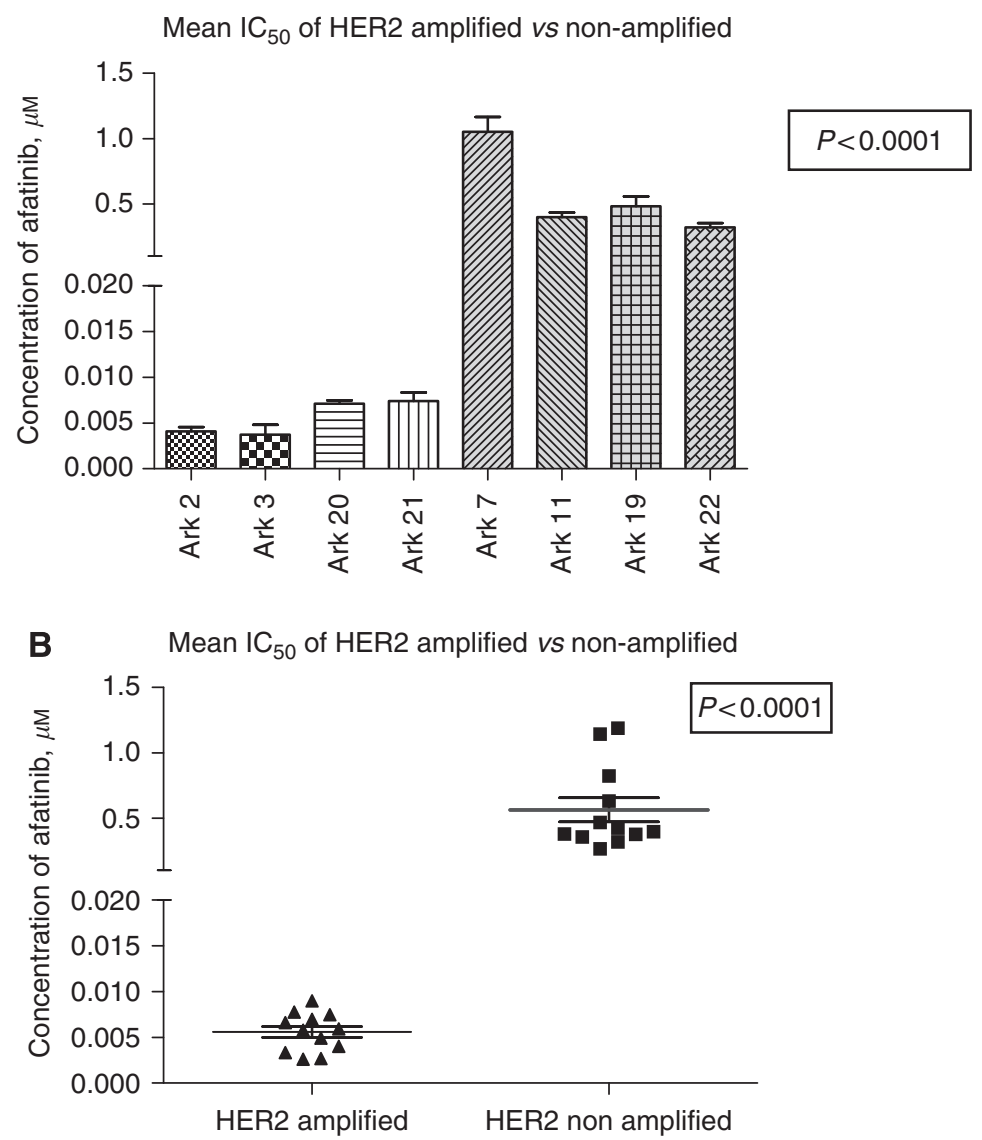

Figure 1. Comparison of mean IC 50 values between HER2-amplified and -non-amplified cell lines. (A) Comparison of mean IC ${ }_{50}$ values for each HER2-amplified and -non-amplified cell line run in triplicate. (B) Comparison of the overall mean IC 50 values for HER2-amplified and -non-amplified cell lines each represented in triplicate.

\section{MFI of ErbB1 in HER2 amplified \\ vs \\ non-amplified cell lines}

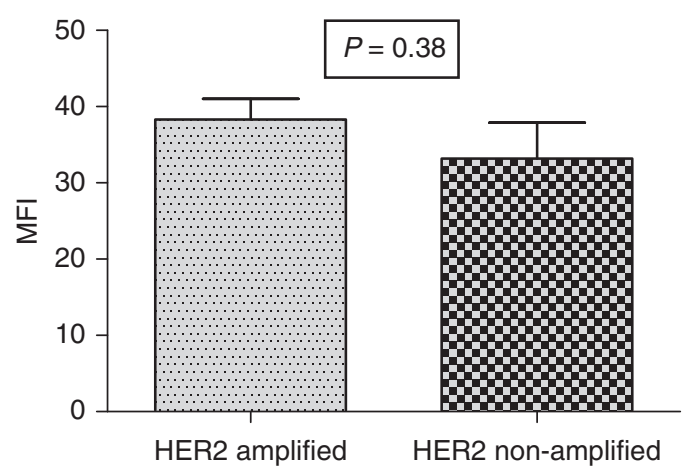

Figure 2. Comparison of mean fluorescence intensity (MFI) of ErbB1 in HER2-amplified vs -non-amplified cell lines. The figure depicts a comparison of the MFI of ErbB1 by direct staining as detected using flow cytometry between HER2-amplified and -non-amplified cell lines.

using $50 \mathrm{~nm}$ of afatinib, revealed that there was a decrease in the phosphorylation of HER2 and S6 reaching its nadir at $10 \mathrm{~h}$ (data not shown). Thus, $10 \mathrm{~h}$ was selected as the optimal time point for the analysis of changes in HER2 and S6 phosphorylation using the $\mathrm{IC}_{50}$ and approximate human serum concentrations of afatinib after administration of $40-50 \mathrm{mg}$ po daily $(5 \mathrm{~nm}, 50 \mathrm{~nm}$, and $175 \mathrm{~nm}$ ).

After incubation of ARK2 for $10 \mathrm{~h}$ with afatinib, cells were harvested and the phosphorylation of HER2 and S6 were analysed (Figure 4A and B). Comparisons of MFIs for phospho-HER2 revealed that there was a significant decrease in phosphorylation at $10 \mathrm{~h}$ with $5 \mathrm{~nm}$ (MFI 48.92 $\pm 1.39, \quad P=0.025), 50 \mathrm{~nm}$ (MFI $24.8 \pm 1.5, P=0.004)$, and $175 \mathrm{~nm}($ MFI $28.08 \pm 1.795, P=0.005)$ when compared with untreated ARK2 (MFI 62.6 \pm 1.735 ). Similarly, analysis of phospho-S6 revealed a significant decrease in the MFI for the protein at $10 \mathrm{~h}$ with $5 \mathrm{~nm}$ (MFI $48.92 \pm 1.139$, $P=0.0018$ ), $50 \mathrm{~nm}$ (MFI 24.80 $\pm 1.5, P=0.007), 175 \mathrm{~nm}$ (MFI $27.09 \pm 1.13, P=0.0004)$ compared with untreated ARK2 (MFI $81.58 \pm 0.085)$. After review of the literature, it appears that this is the first time a decrease in the phosphorylation of HER2/neu in uterine serous cancers, after treatment with a tyrosine kinase inhibitor, has been shown. These data suggest that tumours reliant upon HER2 amplification as a driver for proliferation are indeed susceptible to treatment with afatinib in vitro. Afatinib exhibits remarkable efficacy in vitro, thus we would expect similar efficacy in vivo.

Determination of the efficacy of afatinib in HER2-amplified xenografts. An in vivo model was established by injecting 10 SCID mice with ARK2. Tumours were allowed to establish until they reached a diameter of at least $0.5 \mathrm{~cm}$. Mice were treated with $25 \mathrm{mg} \mathrm{kg}^{-1}$ of afatinib by oral gavage daily, which is the same 

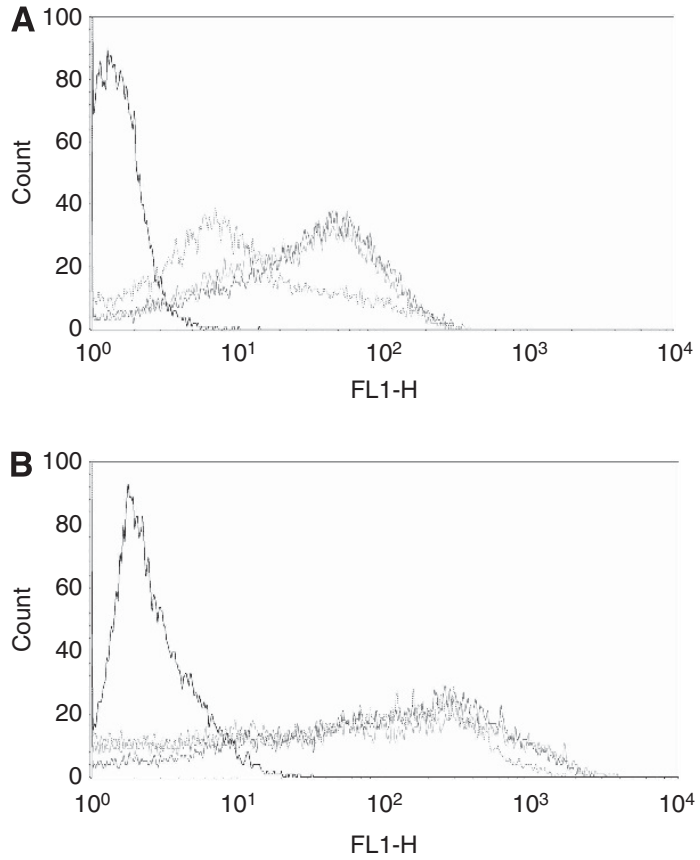

Figure 3. Representative changes in S6 phosphorylation with afatinib treatment HER2-amplified vs -non-amplified cell lines. Representative changes in phosphorylation of the transcription factor S6 after treatment with scalar amounts of afatinib in (A) HER2-amplified (ARK2) and (B) -non-amplified (ARK11) cell lines $8 \mathrm{~h}$ after treatment.

dosage used in other preclinical cancer models (Regales et al, 2009; (Janjigian et al, 2013). Mice treated with vehicle alone had faster tumour growth and were ultimately killed at an earlier time point because of tumour burden. Afatinib treatment resulted in tumour shrinkage or a markedly slower rate of tumour growth and a significant improvement in the duration of overall survival (Figures $5 \mathrm{~A}$ and $\mathrm{B}$ ). These data suggest that afatinib given by oral gavage daily is an effective therapy for HER2-amplified USC.

\section{DISCUSSION}

Uterine serous carcinoma is uniformly fatal when there is recurrence. Currently cytotoxic chemotherapy remains the gold standard of treatment in patients with advanced/recurrent disease. Newer targeted therapies are being developed as a result of evolving knowledge of the genetic landscape of multiple cancers including uterine serous cancers. Although these therapies are undergoing development and new targets are being elucidated, targeting of known driver mutations is paramount in establishing new therapies for highly pretreated malignancies.

Amplification of HER2/neu is associated with more aggressive tumour biology in a number of cancers including breast, ovarian, gastric, and uterine carcinoma (Wright et al, 1989; Berchuck et al, 1990; Hetzel et al, 1992; Tanner et al, 2005). As a result it has been a target of therapy for the past decade. Trastuzumab has been at the fore front of the majority of clinical studies and has shown the most promise in the treatment of HER2-amplified breast cancers. The effectiveness of trastuzumab in the treatment of HER2amplified breast cancer and the discovery of HER2/neu expression in endometrial cancer lead to clinical trials in endometrial cancer (Santin et al, 2002; Fleming et al, 2010). The GOG looked into the effectiveness of trastuzumab in the treatment of a heterogeneous group of endometrial cancers. They concluded that it was not an effective treatment option (Fleming et al, 2010). Newer trials have
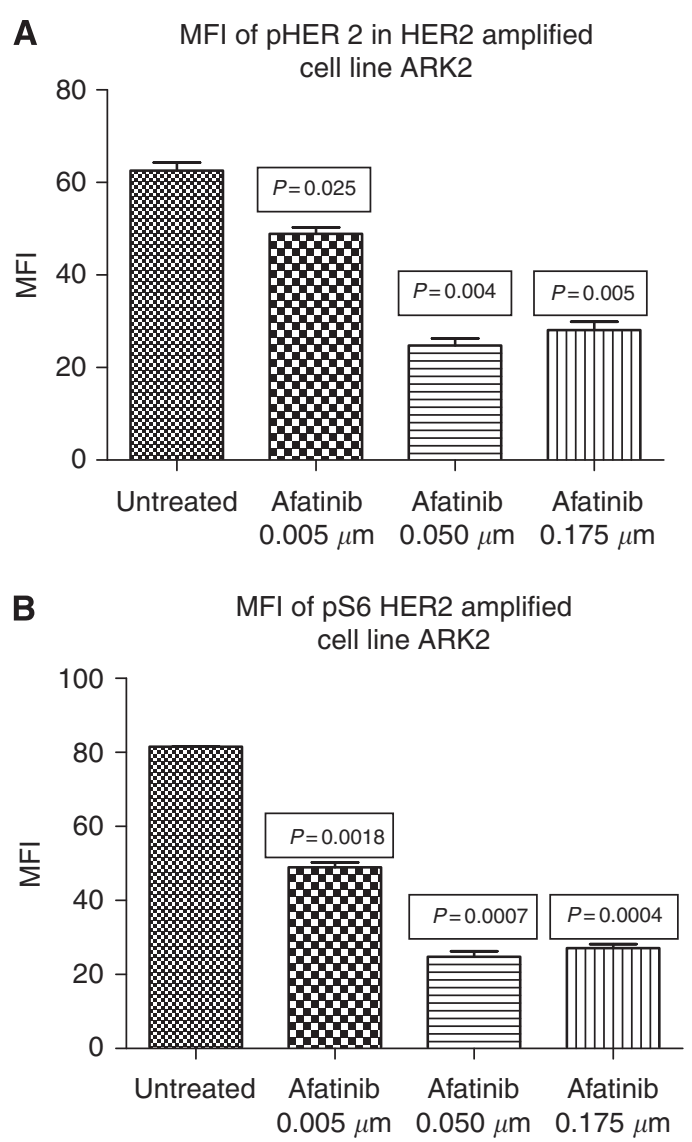

Figure 4. Comparison of mean fluorescence intensity (MFI) for phosphorylated HER2 and phosphorylated S6. Comparison of the MFI of phosphorylated HER2 (A) and phosphorylated S6 at $10 \mathrm{~h}$ (B) in HER2amplified cell line ARK 2 after treatment with afatinib at a concentration of $5 \mathrm{~nm}\left(\mathrm{I} \mathrm{C}_{50}\right), 50 \mathrm{~nm}$ (human serum concentration after $24 \mathrm{~h}$ of $40 \mathrm{mg}$ of afatinib by mouth), and $175 \mathrm{~nm}$ (human serum concentration after 28 days of $40 \mathrm{mg}$ of afatinib by mouth daily).

been designed for women with more homogeneous tumour histology, HER2-amplified USC. Although these trials were being designed new drugs were brought to market for use in non-small cell lung cancer that target the ErbB family of receptors. Afatinib is one of these drugs.

The data and results presented in this study demonstrate afatinib's efficacy against HER2/neu-amplified USC. When cells are exposed to nanomolar quantities of the drug HER2/neu phosphorylation is decreased. These changes in the phosphorylation of HER2/neu correspond to downstream inhibition of S6 phosphorylation and cell cycle arrest as demonstrated by a build up in the G1 phase of the cell cycle. Ultimately, when afatinib is given to mice harbouring HER2/neu-amplified tumours a decrease in the size of tumours is noted over a 30 day period. This corresponds to an improvement in overall survival for mice treated with afatinib.

These data are similar to data published in the preclinical study of afatinib's effect on EGFR-mutated non-small cell lung cancer (Li et al, 2008). Although these tumours are not equivocal to endometrial cancer, the reliance upon the ErbB receptor mutations or amplification are held in common. Clinical trials that were designed based on the aforementioned preclinical data showed an increase in progression-free survival from 6.9 to 11.1 months in patients with EGFR-mutated non-small cell lung cancer (Sequist et al, 2013). The primary toxicities of the drug included diarrhoea and rash. Given afatinib's activity, overall safety, and tolerable side effect profile, afatinib was FDA approved for first-line treatment of these cancers (Dungo and Keating, 2013). Furthermore, data from 

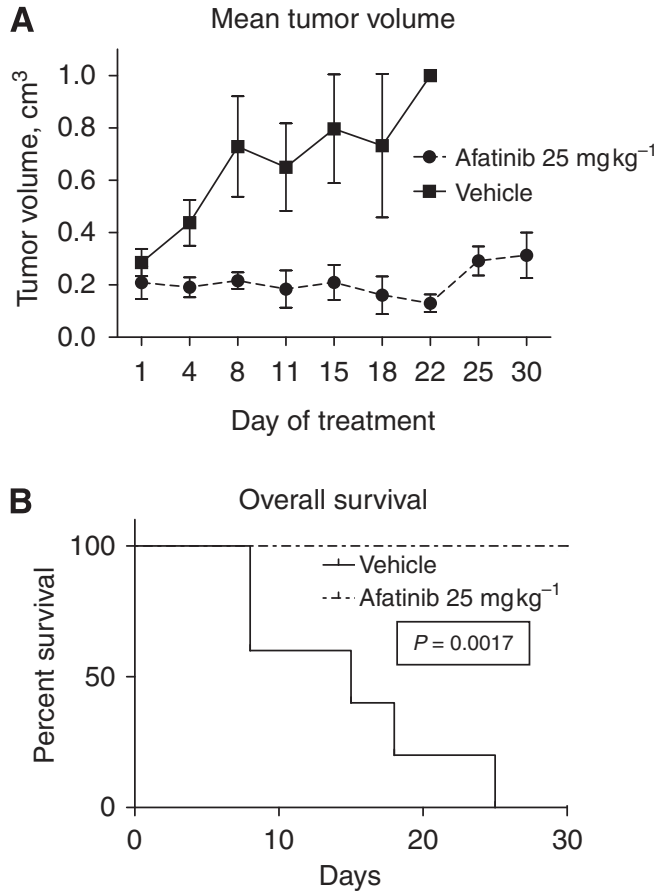

Figure 5. Comparison of mean tumour volume and overall survival in mice treated with afatinib vs vehicle. (A) Comparison of mean tumour size between vehicle and afatinib-treated mice harbouring xenografts of ARK2. (B) Comparison of overall survival in mice harbouring ARK2 xenografts that were treated with afatinib daily or with vehicle.

the breast cancer literature suggest that afatinib provides clinical benefit in patients with HER2-amplified tumours that have been heavily pretreated with chemotherapy and trastuzumab (Lin et al, 2012). Other reports show that afatinib is active, in vitro and in vivo, against tumours that are known to be resistant to trastuzumab treatment (Hickish et al, 2009; Solca et al, 2010). A phase III trial, LUX-breast I, is currently enrolling and is designed to compare trastuzumab with afatinib as first-line treatment in HER2-amplified breast cancer (NCT01125566). The results of the trial are highly anticipated because they may change the treatment paradigm in HER2/neu-amplified breast cancer. The data available in the breast cancer literature give credence to the possibility of using afatinib in HER2-amplified uterine serous cancers that display resistance to trastuzumab. Currently there are no ongoing trials with afatinib in patients harbouring HER2-amplified USC or other gynecologic malignancy. However, there has been one case report of a marked response to afatinib in a heavily pretreated patient with HER2-amplified USC (Talwar and Cohen, 2012).

The preclinical data presented in this study suggest that the FDA approved oral agent afatinib, given as a single dose daily, may provide another treatment option for patients with HER2amplified USC. Given these findings a well-designed clinical trial using afatinib for the treatment of HER2/neu-amplified USC should be considered.

\section{REFERENCES}

Acharya S, Hensley ML, Montag AC, Fleming GF (2005) Rare uterine cancers. Lancet Oncol 6(12): 961-971.

Berchuck A, Kamel A, Whitaker R, Kerns B, Olt G, Kinney R, Soper JT, Dodge R, Clarke-Pearson DL, Marks P, McKenzie S, Yin S, Bast RC Jr (1990)

Overexpression of HER-2/neu is associated with poor survival in advanced epithelial ovarian cancer. Cancer Res 50(13): 4087-4091.
Black JD, English DP, Roque DM, Santin AD (2014) Targeted therapy in uterine serous carcinoma: an aggressive variant of endometrial cancer. Womens Health 10(1): 45-57.

Buza N, English DP, Santin AD, Hui P (2013) Toward standard HER2 testing of endometrial serous carcinoma: 4-year experience at a large academic center and recommendations for clinical practice. Mod Pathol 26(12): 1605-1612.

Cohen RB (2014) Current challenges and clinical investigations of epidermal growth factor receptor (EGFR)- and ErbB family-targeted agents in the treatment of head and neck squamous cell carcinoma (HNSCC). Cancer Treat Rev 40(4): 567-577.

Dungo RT, Keating GM (2013) Afatinib: first global approval. Drugs 73(13): 1503-1515.

Engelsen IB, Stefansson IM, Beroukhim R, Sellers WR, Meyerson M, Akslen LA, Salvesen HB (2008) HER-2/neu expression is associated with high tumor cell proliferation and aggressive phenotype in a population based patient series of endometrial carcinomas. Int J Oncol 32(2): 307-316.

English DP, Bellone S, Cocco E, Bortolomai I, Pecorelli S, Lopez S, Silasi DA, Schwartz PE, Rutherford T, Santin AD (2013) Oncogenic PIK3CA gene mutations and HER2/neu gene amplifications determine the sensitivity of uterine serous carcinoma cell lines to GDC-0980, a selective inhibitor of Class I PI3 kinase and mTOR kinase (TORC1/2). Am J Obstet Gynecol 209(5): 465 e1-465 e9.

Fleming GF, Sill MW, Darcy KM, McMeekin DS, Thigpen JT, Adler LM, Berek JS, Chapman JA, DiSilvestro PA, Horowitz IR, Fiorica JV (2010) Phase II trial of trastuzumab in women with advanced or recurrent, HER2-positive endometrial carcinoma: a Gynecologic Oncology Group study. Gynecolo Oncol 116(1): 15-20.

Goff BA (2005) Uterine papillary serous carcinoma: what have we learned over the past quarter century? Gynecol Oncol 98(3): 341-343.

Hickish T, Wheatley D, Lin N, Carey L, Houston S, Mendelson D, Solca F, Uttenreuther-Fischer M, Jones H, Winer E (2009) Use of BIBW 2992, a novel irreversible EGFR/HER1 and HER2 tyrosine kinase inhibitor to treat patients with HER2-positive metastatic breast cancer after failure of treatment with trastuzumab. Cancer Res 69(Suppl 3): 5060.

Hamilton CA, Cheung MK, Osann K, Chen L, Teng NN, Longacre TA, Powell MA, Hendrickson MR, Kapp DS, Chan JK (2006) Uterine papillary serous and clear cell carcinomas predict for poorer survival compared to grade 3 endometrioid corpus cancers. Br J Cancer 94(5): 642-646.

Hartman Z, Zhao H, Agazie YM (2013) HER2 stabilizes EGFR and itself by altering autophosphorylation patterns in a manner that overcomes regulatory mechanisms and promotes proliferative and transformation signalling. Oncogene 32(35): 4169-4180.

Hetzel DJ, Wilson TO, Keeney GL, Roche PC, Cha SS, Podratz KC (1992) HER-2/neu expression: a major prognostic factor in endometrial cancer. Gynecol Oncol 47(2): 179-185.

Janjigian YY, Viola-Villegas N, Holland JP, Divilov V, Carlin SD, GomesDaGama EM, Chiosis G, Carbonetti G, de Stanchina E, Lewis JS (2013) Monitoring afatinib treatment in HER2-positive gastric cancer with $18 \mathrm{~F}$ FDG and 89Zr-trastuzumab PET. J Nucl Med 54(6): 936-943.

Levenback C, Burke TW, Silva E, Morris M, Gershenson DM, Kavanagh JJ, Wharton JT (1992) Uterine papillary serous carcinoma (UPSC) treated with cisplatin, doxorubicin, and cyclophosphamide (PAC). Gynecol Oncol 46(3): 317-321.

Li D, Ambrogio L, Shimamura T, Kubo S, Takahashi M, Chirieac LR, Padera RF, Shapiro GI, Baum A, Himmelsbach F, Rettig WJ, Meyerson M, Solca F, Greulich H, Wong KK (2008) BIBW2992, an irreversible EGFR/HER2 inhibitor highly effective in preclinical lung cancer models. Oncogene 27(34): 4702-4711.

Lin NU, Winer EP, Wheatley D, Carey LA, Houston S, Mendelson D, Munster P, Frakes L, Kelly S, Garcia AA, Cleator S, Uttenreuther-Fischer M, Jones H, Wind S, Vinisko R, Hickish T (2012) A phase II study of afatinib (BIBW 2992), an irreversible ErbB family blocker, in patients with HER2-positive metastatic breast cancer progressing after trastuzumab. Breast Cancer Res Treat 133(3): 1057-1065.

Mitri Z, Constantine T, O’Regan R (2012) The HER2 receptor in breast cancer: pathophysiology, clinical use, and new advances in therapy. Chemother Res Pract 2012: 743193.

Modjtahedi H, Cho BC, Michel MC, Solca F (2014) A comprehensive review of the preclinical efficacy profile of the ErbB family blocker afatinib in cancer. Naunyn Schmiedebergs Arch Pharmacol 387(6): 505-521.

Nicklin JL, Copeland LJ (1996) Endometrial papillary serous carcinoma: patterns of spread and treatment. Clin Obstet Gynecol 39(3): 686-695. 
Regales L, Gong Y, Shen R, de Stanchina E, Vivanco I, Goel A, Koutcher JA, Spassova M, Ouerfelli O, Mellinghoff IK, Zakowski MF, Politi KA, Pao W (2009) Dual targeting of EGFR can overcome a major drug resistance mutation in mouse models of EGFR mutant lung cancer. J Clin Inves 119(10): 3000-3010.

Reungwetwattana T, Dy GK (2013) Targeted therapies in development for non-small cell lung cancer. J Carcinog 12: 22.

Santin AD, Bellone S, Gokden M, Palmieri M, Dunn D, Agha J, Roman JJ, Hutchins L, Pecorelli S, O’Brien T, Cannon MJ, Parham GP (2002) Overexpression of HER-2/neu in uterine serous papillary cancer. Clin Cancer Res 8(5): 1271-1279.

Santin AD, Bellone S, Van Stedum S, Bushen W, Palmieri M, Siegel ER, De Las Casas LE, Roman JJ, Burnett A, Pecorelli S (2005) Amplification of c-erbB2 oncogene: a major prognostic indicator in uterine serous papillary carcinoma. Cancer 104(7): 1391-1397.

Schwartz PE (2006) The management of serous papillary uterine cancer. Curr Opin Oncol 18(5): 494-499.

Sequist LV, Yang JC, Yamamoto N, O’Byrne K, Hirsh V, Mok T, Geater SL, Orlov S, Tsai CM, Boyer M, Su WC, Bennouna J, Kato T, Gorbunova V, Lee KH, Shah R, Massey D, Zazulina V, Shahidi M, Schuler M (2013) Phase III study of afatinib or cisplatin plus pemetrexed in patients with metastatic lung adenocarcinoma with EGFR mutations. J Clin Oncol 31(27): 3327-3334.

Solca F, Adolf GR, Jones H, Uttenreuther-Fischer MM (2010) Beyond trastuzumab: second-generation targeted therapies for HER2-positive breast cancer. Drugs for HER-2-positive Breast Cancer, Milestones in Drug Therapy, Sibilia M, Zielinski CC, Bartsch R, Grunt TW pp 91-107. Springer Science, Business Media LLC: New York, Philadelphia.

Takezawa K, Pirazzoli V, Arcila ME, Nebhan CA, Song X, de Stanchina E, Ohashi K, Janjigian YY, Spitzler PJ, Melnick MA, Riely GJ, Kris MG,
Miller VA, Ladanyi M, Politi K, Pao W (2012) HER2 amplification: a potential mechanism of acquired resistance to EGFR inhibition in EGFR-mutant lung cancers that lack the second-site EGFRT790M mutation. Cancer Discov 2(10): 922-933.

Talwar S, Cohen S (2012) Her-2 targeting in uterine papillary serous carcinoma. Gynecol Oncol Case Rep 2(3): 94-96.

Tanner M, Hollmen M, Junttila TT, Kapanen AI, Tommola S, Soini Y, Helin H, Salo J, Joensuu H, Sihvo E, Elenius K, Isola J (2005) Amplification of HER-2 in gastric carcinoma: association with Topoisomerase IIalpha gene amplification, intestinal type, poor prognosis and sensitivity to trastuzumab. Ann Oncol 16(2): 273-278.

Wright C, Angus B, Nicholson S, Sainsbury JR, Cairns J, Gullick WJ, Kelly P, Harris AL, Horne CH (1989) Expression of c-erbB-2 oncoprotein: a prognostic indicator in human breast cancer. Cancer Res 49(8): 2087-2090.

Zhao S, Choi M, Overton JD, Bellone S, Roque DM, Cocco E, Guzzo F, English DP, Varughese J, Gasparrini S, Bortolomai I, Buza N, Hui P, Abu-Khalaf M, Ravaggi A, Bignotti E, Bandiera E, Romani C, Todeschini P, Tassi R, Zanotti L, Carrara L, Pecorelli S, Silasi DA, Ratner E, Azodi M, Schwartz PE, Rutherford TJ, Stiegler AL, Mane S, Boggon TJ, Schlessinger J, Lifton RP, Santin AD (2013) Landscape of somatic single-nucleotide and copy-number mutations in uterine serous carcinoma. Proc Natl Acad Sci USA 110(8): 2916-2921.

This work is published under the standard license to publish agreement. After 12 months the work will become freely available and the license terms will switch to a Creative Commons AttributionNonCommercial-Share Alike 3.0 Unported License. 